\title{
Article \\ Application of VR Technology to the Training of Paramedics
}

\author{
Martin Boros ${ }^{1, *(\mathbb{D})}$, Eva Sventekova ${ }^{1}$, Anna Cidlinova ${ }^{2}$, Marek Bardy ${ }^{3}$ and Katerina Batrlova ${ }^{2}$ \\ 1 Faculty of Security Engineering, University of Zilina, Univerzitna 8215/1, 01026 Zilina, Slovakia; \\ eva.sventekova@uniza.sk \\ 2 Occupational Safety Research Institute, Jeruzalémská 1283/9, 11000 Praha, Czech Republic; \\ cidlinova@vubp-praha.cz (A.C.); batrlova@vubp-praha.cz (K.B.) \\ 3 XR Institute s.r.o., Zbrojnická 229/1, 30100 Pilsen, Czech Republic; bardy@cie-group.cz \\ * Correspondence: martin.boros@uniza.sk
}

check for

updates

Citation: Boros, M.; Sventekova, E.; Cidlinova, A.; Bardy, M.; Batrlova, K. Application of VR Technology to the Training of Paramedics. Appl. Sci. 2022, 12, 1172. https://doi.org/ 10.3390/app12031172

Academic Editors:

Valentino Santucci, Alfredo Milani and Fabio Caraffini

Received: 15 November 2021

Accepted: 21 January 2022

Published: 23 January 2022

Publisher's Note: MDPI stays neutral with regard to jurisdictional claims in published maps and institutional affiliations.

Copyright: (c) 2022 by the authors. Licensee MDPI, Basel, Switzerland. This article is an open access article distributed under the terms and conditions of the Creative Commons Attribution (CC BY) license (https:/ / creativecommons.org/licenses/by/ $4.0 /)$.

\begin{abstract}
The virtual world has long been a focus not only of the gaming sphere, but also of the manufacturing and educational industries. The virtual world and its technology have many advantages, the basic ones being, for example, the use of experiential learning, with which the human brain can remember some things better and faster. It was due to the advantages of virtual reality technology that we decided to create an educational system on safety and health at work, and we focused on the healthcare segment due to the COVID-19 pandemic. Thanks to the cooperation of a professional consortium, we created an educational system for safety and health at work and carried out several extensive laboratory measurements, the results of which we followed up in practical measurements with medical staff. The created system is inherently unique and applicable and can be used across several industries. The article presents three basic types of scenarios as well as an evaluation of satisfaction with the proposed system from test participants, i.e., nurses.
\end{abstract}

Keywords: virtual reality; safety and health at work; education system; testing

\section{Introduction}

The virtual world and virtual space are names that represent unreal environments created by computers. We can understand these terms from two perspectives, one of which the virtual space of social networking sites, such as online chat rooms, chat dating sites, and similar others. Within this group, we can express our opinions and attitude towards situations, persons, and the like without worrying about what others will think of us, since we do not have to go by our name but, for example, can use a nickname, i.e., impersonate anyone else. Many people use this method, which is why the notion that we can do everything on the Internet has become popular. The second perspective is the virtual media space, which primarily refers to the gaming space, which can show a higher profit value on a long-term, year-on-year basis. Among other things, the virtual world can be understood as a communication medium within which it is very difficult to define the difference between the virtual and the real world [1]. On the contrary, several authors see the virtual world as a future or a new uprising for some industries, such as museums or galleries, thus supporting artists [2,3]. It is the virtual world that can provide us with a sense of everyday life, despite the current impact of the COVID-19 pandemic, when attendance at several social events or cultural events is limited or completely canceled $[3,4]$.

According to Newzoo [5], in 2022, the virtual reality industry should be worth \$196 trillion, and this amount includes all platforms that enable gaming, such as console, PC, mobile, tablet, and others. Games are a very popular way for many of us to relax, without even realizing that we are being transported into a virtual world where we could be a professional soldier, an athlete, or anyone else. Although the prevailing opinion in the past was that those who play a lot of games are gamers, the opposite is in fact true, at least in some cases, such that gamers are slowly becoming 'professional athletes', whom we may one day 
see in the Olympics. With the gradual evolution of modern technology, gaming platforms have also evolved and gradually found popularity with most users; these are mainly the Xbox with Kinect, Nintendo Wii, and others, where some of the controls can be defined by user gestures. The procedure described above is similar for virtual reality (hereafter VR), which is gradually finding an increasingly stable place in the technological equipment of the average user [6].

VR is an unrealistic, simulated environment created by a computer. This term is often misused, as many end-users consider even a classic video game to be VR, and the term is also often confused with the term virtual world. However, VR differs from classic games in its essence, and this is the complete immersion of the user in the action, using specialized devices such as goggles, controllers, projector arrays, and the like. When using VR, we have a very intense visual sensation, and we feel that we are in a completely different sensory place. There is a certain disadvantage in the fact that we can eliminate the surrounding environment, and in the case of not creating enough surrounding space, accidents can occur. In addition to the notion of VR in virtual space, we distinguish two kinds of realities, namely Augmented Reality (hereafter AR) and Mixed Reality (hereafter MR). AR represents the combination of the real world with the addition of unrealistic $2 \mathrm{D}$ or $3 \mathrm{D}$ objects. The advantage of this kind of reality and the associated glasses is that several types are made for one eye only, as also shown in Figure 1, and can be conveniently slid up on the head and retracted again when needed. MR, or for some authors, hybrid reality or second-generation AR, exploits the capabilities of 3D objects applied to real-world environments. Undoubtedly, the advantages of MR include the ability to be controlled by gestures without the need for additional controllers, as is the case with VR. On the other hand, VR is several times cheaper than AR in terms of cost $[7,8]$.

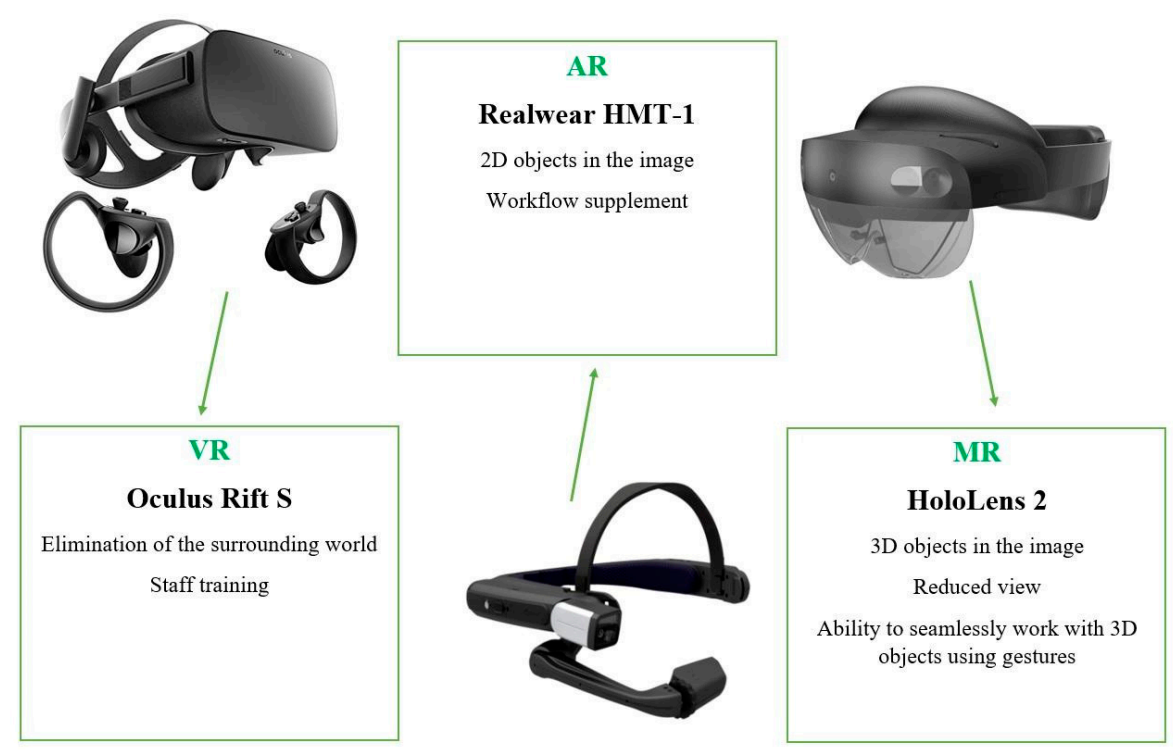

Figure 1. The difference between the glasses of each type of reality [7].

As we can see, in Figure 1, VR is the only type of reality that needs special elements for control-joysticks, with which the user can confirm the session itself within another reality. The aforementioned elimination is both an advantage and a disadvantage of VR, since from the modeling point of view of environment creation, VR is the simplest compared to the others. VR is the most commonly commercialized of these technologies, as it has the greatest potential in terms of cost/use ratio $[9,10]$. MR and subsequently AR have been developed for much more specific uses and are still waiting for their permanent deployment within the commercial sphere. Applications of these realities include architectural design [11], learning to treat selected surgical procedures [12], and training of security forces [13,14].

Unlike MR and AR, VR has a relatively wide range of applicability, e.g., video games, live events, virtual parks, cinema movies, modern gadgets, and education. With the 
gradual transformation of needs, VR, especially from the gaming sphere, has moved into commercial use, where its essence and the use of experiential learning has been applied. According to Gran view's research [15], the global market size was estimated to be worth $\$ 15.6$ trillion in 2020, and it is estimated that this value will increase by $18 \%$ by 2028 . The demand for VR is particularly felt in the instructional training of new workers, or in the recurrent training of mechanics, pilots, soldiers, or oil industry workers, industries where, from the point of view of the importance of the work activity, it is worth investing in the development of a tool that will show the worker the consequences of its possible failure.

According to [16], the virtual market value in the healthcare segment is projected to be $\$ 2.4$ trillion in 2026, approximately $14 \%$ of the total expected value. It can be assumed that, given the current situation caused by COVID-19, this value could increase even more. COVID-19 increased interest in VR, especially in real estate, with real estate agents using VR to virtually tour a property, using, for example, a mobile app. In this case, we are talking about VR in 2D. Such use of VR is very simple and convenient for the end user, as they can become familiar with the basic parts of the virtual or even real space using a web browser or a special application. Google Maps also uses a similar principle [17]. On the other hand, the second option is a fully mobile VR in which it is also necessary to acquire technical equipment-helmets and controllers. After this initial investment, there is no need to invest further, only to charge or change the batteries powering the system.

As has been suggested, the essence of the virtual world is the possibility of being and doing something completely different from who we are or what we actually do. Over time, however, some scholars have come to see this space from a different perspective, namely experiential. If someone wants to try a roller-coaster ride but is afraid, they can go first to the one in the virtual world and then to the real one. The same is true for promising pilots who learn how to land an airplane in complicated situations; they will not risk their lives or the lives of their passengers or cause material damage while, but they will learn how to do it in the virtual space. It is scientifically proven that experiential learning is far more effective than classical learning, and students are able to remember more, so the effect of education is obvious. The human brain can better remember what to do in a given situation by means of an experiential situation. Gradually, teachers and schools have understood this and have started to use the virtual world to teach financially demanding subjects $[18,19]$ but also to prepare future teachers for online teaching due to the impact of COVID-19 or other emergency situations [20].

Our concern is the observance of safety precautions, habits aimed at the protection of persons. A typical example of our interest is the computer game Zero Hour: America's Medic [21], in which the user acts as a paramedic whose task is to rescue people and give them first aid after a car accident, a bomb explosion, etc. Thus, the user can use the virtual environment to test whether they are administering proper mouth-to-mouth breathing or other initial actions to save a life. This game should undoubtedly be played by anyone going through any first aid course, such as driving school. For our research, we focused on a similar approach described above but applied it to building a system for safety and health at work (OHS) for different industries in the context ofCOVID-19, from the point of view of the possibility of full-fledged limb control, while the OHS deployment itself is performed only visually [22]. According to the analysis of the applicability of VR in OHS [23], we could reach approximately $84 \%$ of the working population in the Czech Republic with such a system. In addition to the OHS system created by us, we could increase and make more attractive the training of OHS legislation, which every employee must attend at regular intervals. Further, [23] provides a categorization of work sectors with an expression of the expected value of a given area, as shown in Table 1. 
Table 1. Profitability of industries in Czech Republic [23].

\begin{tabular}{cc}
\hline Categorisation for VR & Estimated Segment Value (mil. EUR ) \\
\hline Manufacturing and processing enterprises & 1.54 \\
Technical and Economic workers & 1.09 \\
Retail & 0.91 \\
Healthcare & 0.41 \\
Construction industry & 0.40 \\
\hline
\end{tabular}

Considering the current COVID-19 situation, we decided to focus primarily on healthcare workers, as they work on the front line and the need for OHS compliance is highly desirable for them at this time.

The current situation in the healthcare sector is very risky due to COVID-19, and we could even call the work in this segment the riskiest. It is also because of this incentive that the idea to create such an oriented project aimed at educating health personnel in OHS, through VR, was born. This is an effective and flexible way of retraining workers, which can be offered to workers at the present time and thus increase their knowledge and experience in OHS. Specifically, it is a training software that, in the form of plausible situations / procedures in the environment of health care facilities, will ensure the acquisition of OHS knowledge and skills, thanks to which health care workers increase their knowledge and skills in the subject, and this is associated with an equally important reduction in the number of occupational injuries and other negative impacts related to lack of experience and knowledge.

Due to the adaptability of OHS legislation in a dynamically changing work environment as a result of constant innovation, pressure for flexibility but also the new phenomenon of pandemics, there is a need to modernize the current concept of OHS education in order to meet the requirements of the present time for flexibility and innovative trends but also the possible absence of contact of a larger number of people.

\section{Materials and Methods}

Our goal, as stated in the previous section, was to create an OHS training system applicable to multiple segments of the labor market. For better efficiency and usability of the solution, we decided to create both options for using VR, i.e., VR in 2D and a comprehensive, mobile version. In order to use the VR in 2D in workplaces and the mobile version in training sites, an initial investment is required to procure it.

The aim of the application and overall VR training for medical staff was to improve the technique and training of the correct use of PPE in protection against COVID-19 and in the retraining of staff from other departments to work in the infectious disease department:

1. Correct and accurate procedure for dressing and removing PPE:

(a) Net part of the department

(b) Septic part of the ward

(c) Shift rotation;

2. Principles of using PPE at work;

3. Warnings about the most common errors;

4. Handling of infectious PPE, chemicals, and biological agents.

To achieve the desired goal, we have formed a consortium of institutions: Ministry of Labour and Social Affairs of the Czech Republic, University Hospital in Pilsen, XR Institute and Guard7. The consortium thus formed was awarded a research project, the aim of which was to increase and streamline OHS education as a prevention against contracting COVID-19. For our application, we have chosen a uniform list of personal protective equipment used in all hospitals so that it is possible to use the application nationwide in all medical facilities. This list is as follows:

1. Disposable protective gloves, non-sterile:

- inner gloves-always used 
- $\quad$ outer gloves - the second glove must be used in case of contact with respiratory secretions and in case of work with biological material in blood-borne infectionsHBV, HCV, HIV;

2. 2nd respirator FFP2/3, nanomask;

3. Spectacles or shield (when taking biological material);

4. Disposable headgear;

5. Disposable coat;

6. Overalls;

7. Plastic apron;

8. Leg warmers.

For our needs, it was necessary to meet some conditions such as the creation of a single scenario of the selected situation; this part was dealt with primarily by the staff of the University Hospital in Pilsen who wrote a multi-point scenario. This scenario was subsequently edited by Guard 7 staff, experts in occupational health and safety. In the last stage, the scenario, which was written clearly, was dealt with by the XR Institute, which produced the two required variants of the solution. Given the diversity of the healthcare segment, we decided to create not one but three comprehensive scenarios that can be encountered in most departments, not just the COVID-19 department.

For all scenarios, we had the same solution procedure, which was as follows:

- Initial configuration-selection and familiarization with the avatar.

- Environment-identifying which parts of the hospital campus are involved.

- Scenario - the avatar familiarizes the user with the situation they are in and what is expected of the user. Using an animation video, it shows the user what they should do, and then after the video, the user is allowed to perform each action to see if they have mastered each procedure.

The scenarios represented a separate, very significant task. For their suitability and proper setup, we chose a separate methodology for their creation, which consisted of:

- $\quad$ Assessing the training in terms of the possibilities of implementation using VR;

- Assessment of the technical prerequisites for the implementation of the training;

- $\quad$ Analysis of the key knowledge within the training;

- Detailed analysis of the training-especially its benefits;

- $\quad$ Defining the benefits of VR (experiential learning) versus conventional training methods;

- Design of basic scenarios (interaction, scene dynamics, avatar involvement, sound, dubbing, behavioral techniques);

- $\quad$ Checking for adherence to follow-up processes, etc.;

- Creation of the application;

- $\quad$ Testing in laboratory conditions-premises of XR Institute, s.r.o.;

- Testing in real conditions-University Hospital in Pilsen;

- Implementation into the process-University Hospital in Pilsen.

Testing in real conditions on employees of the University Hospital in Pilsen helped us to find out the contribution of VR, experiential learning to the training process for the use of personal protective equipment at work. The actual testing process in real conditions involved 120 employees of the hospital working in the same departments. The total number was made up of a combination of doctors, nurses, orderlies, and other staff who routinely moved around the ward. Since this is a specific environment, both the hospital and the scenarios were primarily focused on handling potentially hazardous items that hospital employees may come into direct contact with. This was mainly about the proper handling of sharp or dangerous objects such as needles, scalpel, etc. Of course, there was also the correct donning and use of protective equipment such as gowns, disinfection, and hand washing.

The desktop application had no specific requirements during its development; it was designed to be compatible with Windows or Android. For the mobile app, we focused on an app that would be usable on the All-in-One VR goggles, the Oculus Quest. We primarily 
focused on the Oculus Quest glasses for several reasons, such as its $360^{\circ}$ range of use, the compact controllers, and the price of EUR 350. The price was one of the key parameters, as we want to achieve a high range of use of the developed OHS system.

\subsection{Created Scenarios}

We started first with the development of a desktop application for VR in 2D. During its development, we defined requirements focused on intuitive control, elimination of risks, time savings, and a clear standard. The application is created in Czech language for better understandability and applicability. In the future, we are planning a language change into English, after elimination of possible deficiencies found during testing.

The application is based on a computer-modeled situation where the health worker has to take all the precautions, putting on the protective drape, the protective shield, the gloves, the gown, , and so on. The aim of the application is to make it simple and unambiguous. In Figure 2, we can see the screen of the application within which the user has to place the aforementioned, but different protective equipment, on the avatar, while having to observe the correctness of putting them on. Correctness in this case refers to the fact that the protective gloves must be put on under the disposable jacket and not the other way around, and so on. Otherwise, safety precautions would not be observed and the user could be infected in a real situation. If the user chooses the correct procedure for putting on the protective equipment, it will be shown in green, if not, in red. The wizard chooses to use a disposable coat or overall for the helper and follows this procedure to work in the septic department:

1. Disinfection of dressed gloves.

2. Removing the mouthpiece and throwing it into the infectious waste containerfoot-operated.

3. Disinfection of hands or gloves.

4. Fasten hair with an elastic band.

5. Put on the respirator so that the laces (rubber bands) are placed so that the upper ones are just above the ears and the lower ones below the ears; they must not cross. With one hand, hold the respirator in the correct position on the face, and with the other hand, draw the laces over the head. Adjust (shape the metal strip in the upper part) so that it seals mainly on the parts placed on the nose.

6. Wear safety goggles so that the respirator is just below the goggles.

7. Apply disposable headgear.

8. Bottom gloves-if they are not already fitted, the edges will be under the disposable casing.

9. Putting on a disposable coat with the help of an assistant to tie the neck and separately at the waist; the assistant straightens the coat at the back.

10. Leg warmers.

11. Plastic apron over the coat: with the help of an assistant, adjust the length behind the necktie and behind the back.

12. Put on the upper gloves, with the edges pulled over the disposable coat.

13. Fit the protective shield: tighten and adjust the inclination of the shield.

14. Inspect the correct deployment with the help of an assistant.

15. Mark the employee by name with a marker on a plastic apron. Recommended.

16. Knock on the door before entering the patient room.

17. Always disinfect the top gloves after treating the patient and closing the door. Valid after each treatment 


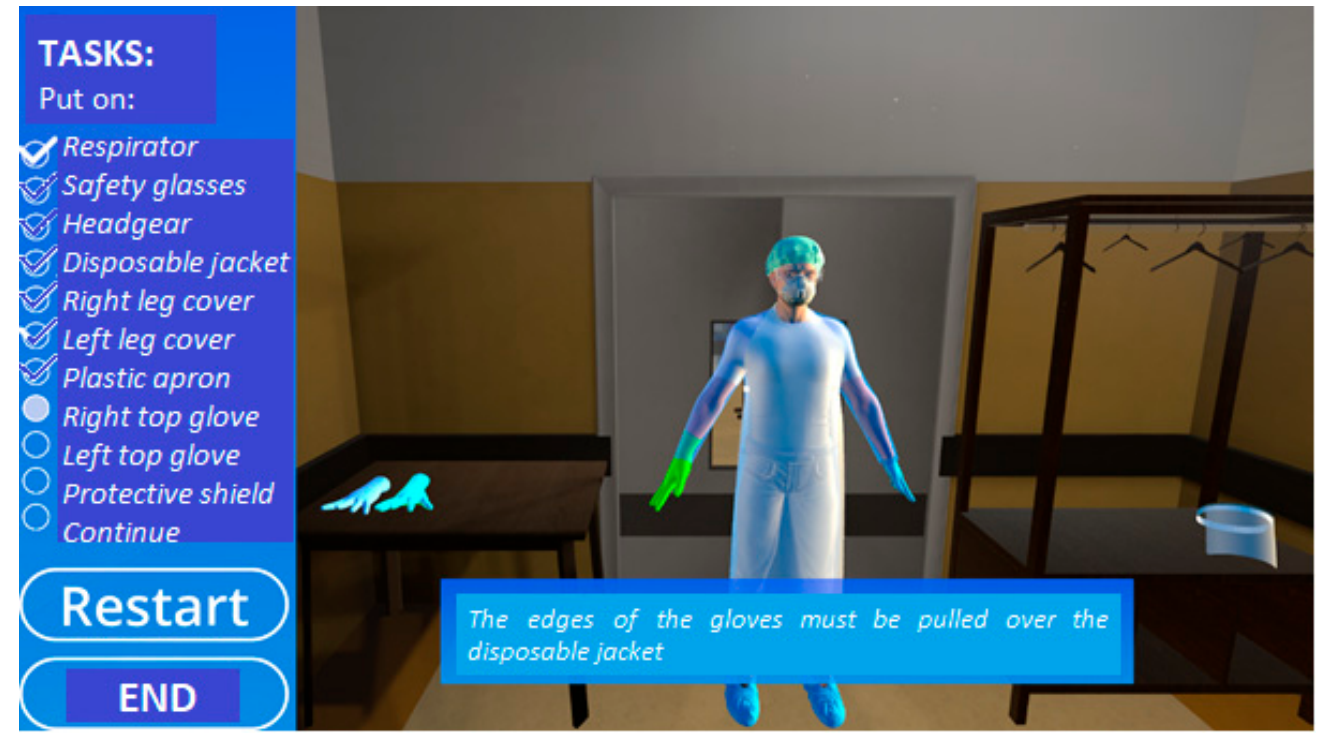

Figure 2. View of the correct placement of personal protective equipment on the avatar.

The second platform we created was the mobile VR itself, aimed to be used with the aforementioned Oculus Quest goggles. In developing this platform application, we focused on the use of real-world environments, direct human interaction with the virtual environment given both the possibilities of physically moving the user around the room. The mobile application is based on the same scenario as the desktop application; however, due to the possibilities, it is supplemented with several supporting capabilities as also shown in Figure 3. In this case, it can be seen how the user has to proceed with the cleaning of the hands in the desired direction and time duration. With such a practical simulation, the user gains more complete habits associated with hand washing.

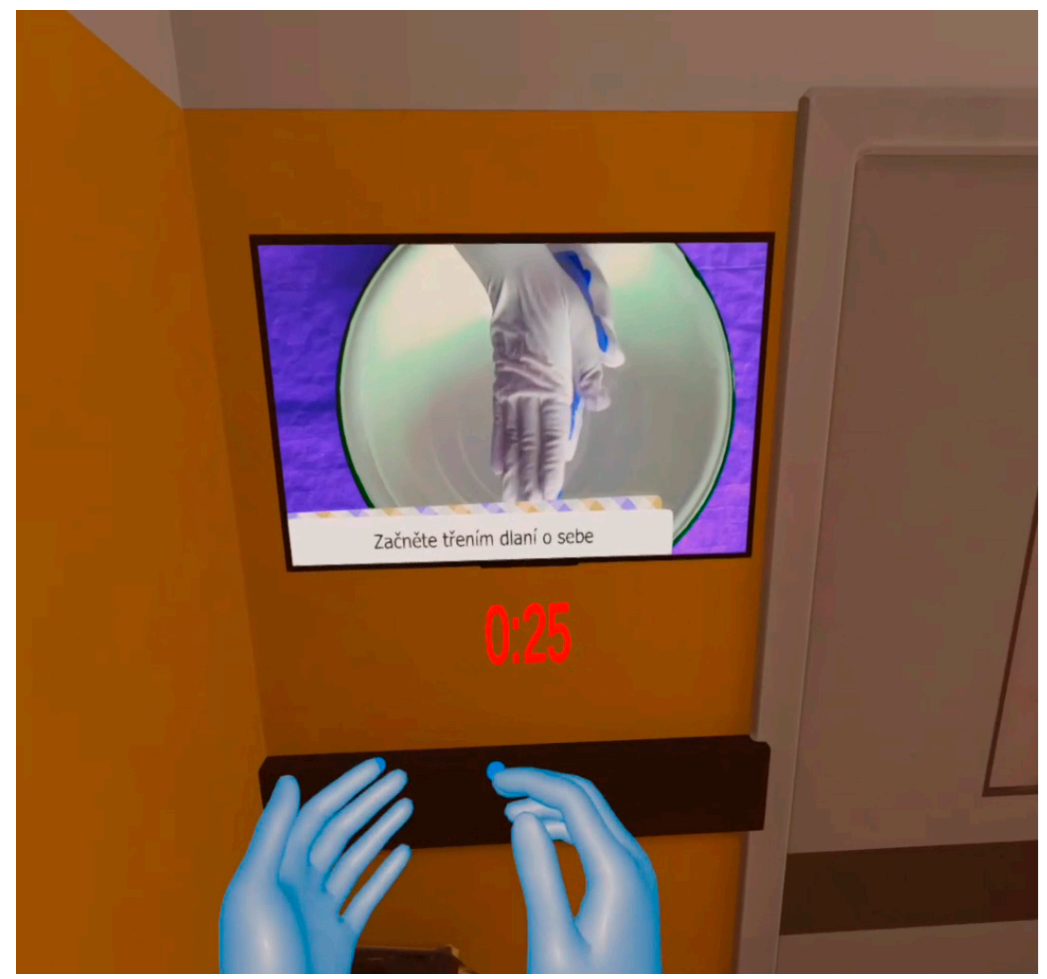

Figure 3. Illustration of proper hand washing together with the time limit required for a thorough cleaning. 


\subsubsection{Handling Sharp Objects}

One training scenario presented is the handling of sharps such as needles and syringes that healthcare workers commonly come into contact with. Such training tends to be a part of the educational studies in high school or college, but often, if students are able to experience it, it is to a minimal degree [24,25]. As part of the training, the scenario includes a person who accompanies the user throughout the entire event and alerts them to essential instructions, supplemented by safety requirements in the real environment, such as that infectious waste bins in the real environment should only be opened with the foot. Figure 4 shows how we are to handle a used syringe. The complete training is built on simplicity and clarity of the teaching material.

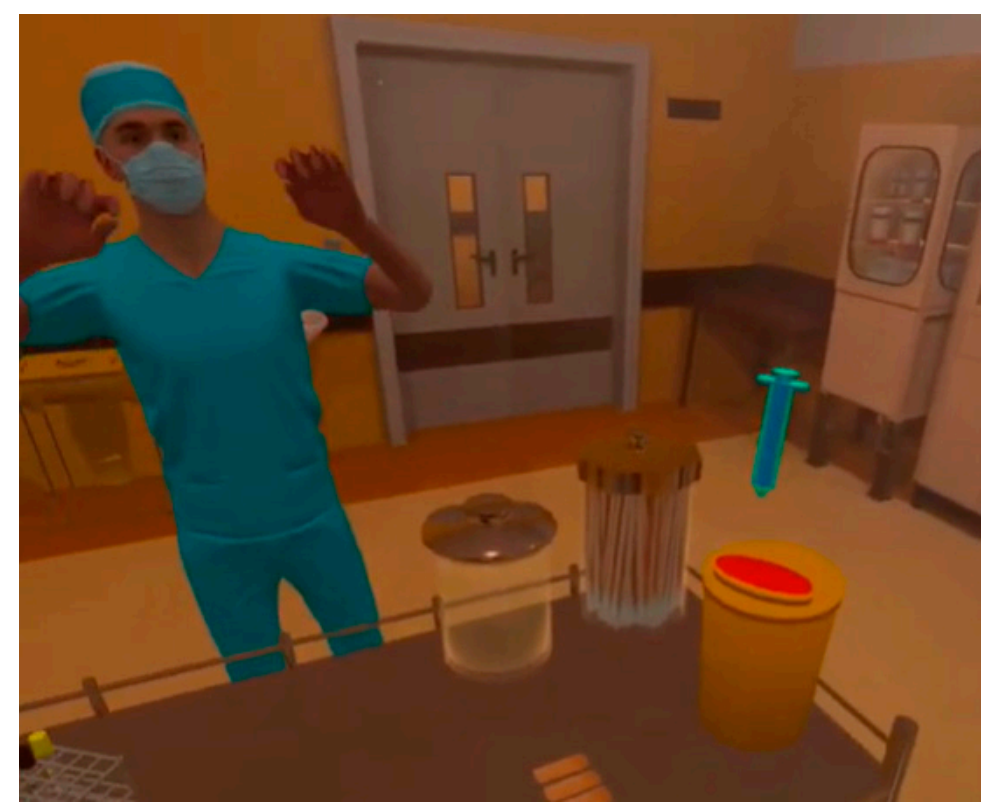

Figure 4. Showing the correct removal of sharp objects.

\subsubsection{Injury by Sharp Objects}

We decided to create a separate training scenario mainly from a preventive point of view, because not everyone knows in advance what kind of patient they will be treating, whether the patient will cooperate, etc. In such cases, accidental injuries often occur to the nursing staff, and it is advisable for them to practice how to act in the case of an injury on their own skin. The scenario we have created focuses on the accidental injury of a manikin and the subsequent handling of the needle, disinfection, and treatment of the injection site as well as instructions on who to report the incident to and what examinations should be carried out as a precautionary measure. In Figure 5, we can see the injured site together with the prepared disinfectants. Alerting about procedures, reporting, and examinations is a very important step, as several surveys indicate that both nurses and physicians fail to report almost one third of injuries [26]. 


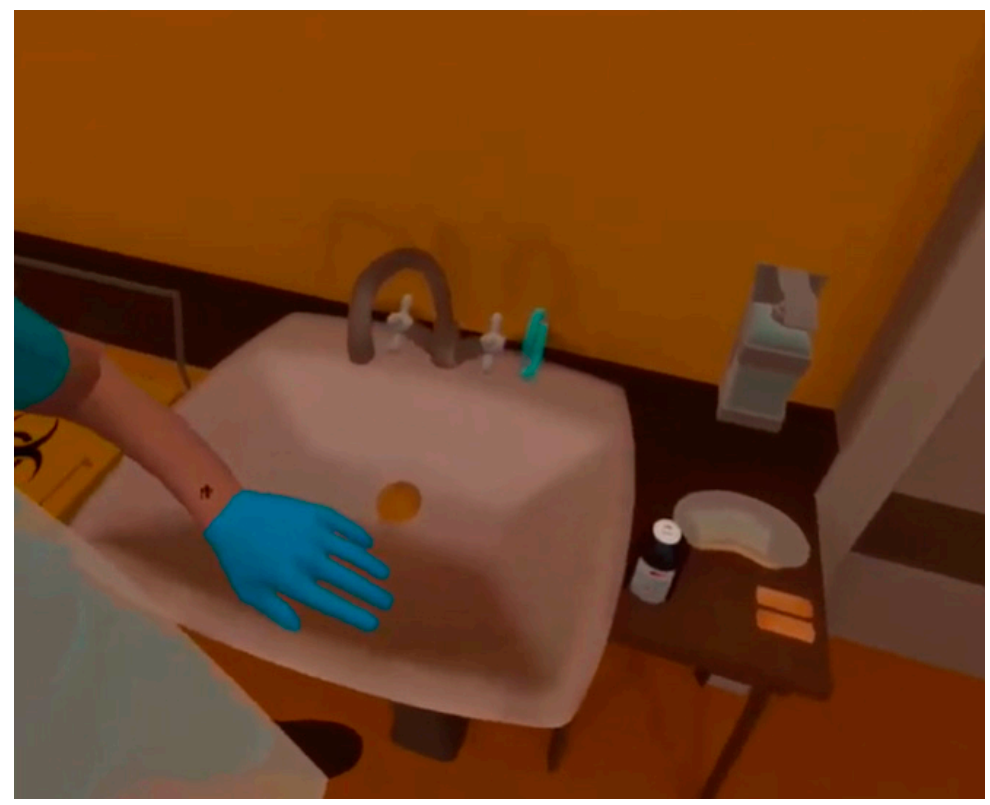

Figure 5. View of the treatment of a sharps injury.

\subsubsection{Procedure for Leaving the Infectious Compartment}

A final and currently very relevant scenario presents the behavior of a person entering a specialized infectious disease ward such as the COVID-19 ward [27]. This is because proper prevention is essential and the use of personal protective equipment such as gowns, respirators, and goggles must be implemented in the right order, be appropriately fitted, and so on. In the case of our scenario, we focused on the need for hand disinfection, putting on the respirator, and then properly folding it and disposing of it into the infectious waste container, as we can see in Figure 6. The training scenario consists of two parts: the first is the handling of personal protective equipment before entering the ward, and then after entering, it switches to the situation after leaving the ward. Thus, the actual stay and work on the ward is not addressed in the scenario.

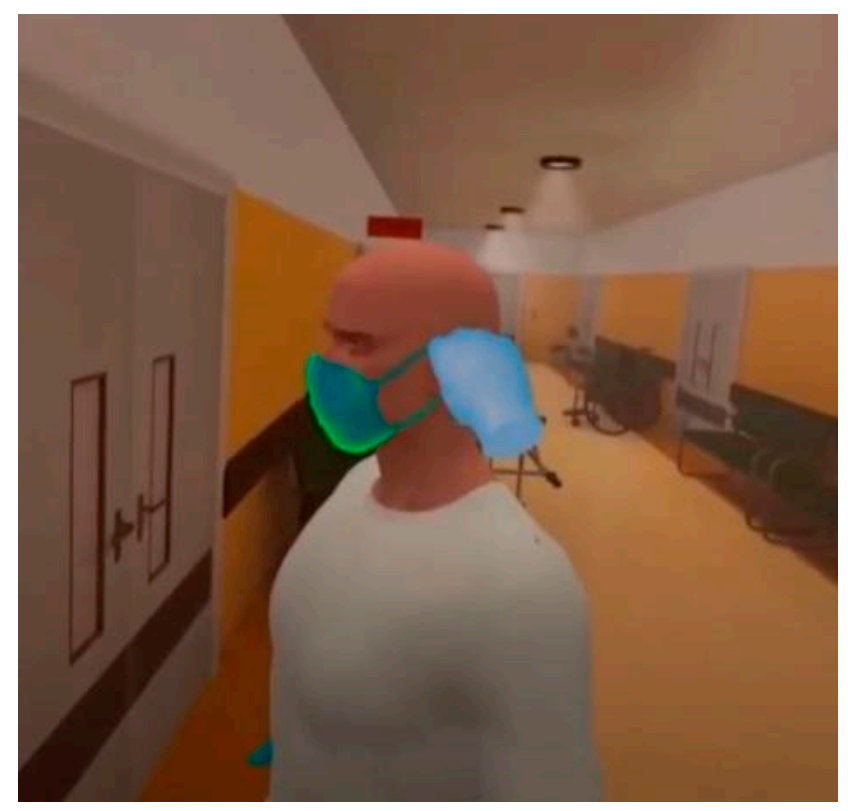

Figure 6. Example of correct deployment of the respirator on the avatar. 
In order to protect mainly medical personnel, it is necessary to perform and follow the correct procedure of removing personal protective equipment, which may be infectious. Therefore, the following procedure would be chosen for this situation:

1. Disinfect the put on upper gloves-min. $30 \mathrm{~s}$.

2. Remove the protective shield behind the rear plastic part - the head sleeve-do not touch the transparent front part.

3. Place the protective shield in a reusable PPE container for disinfection.

4. With the help of an assistant, remove the plastic apron in the forward bend, roll it up, and do not shake or touch the outside of the apron, which may be contaminated.

5. Dispose of the apron in a container for infectious waste-used PPE, i.e., a yellow container marked with the biohazard symbol.

6. Undress the leg warmers.

7. Dispose of the leg warmers in a container for infectious waste-used PPE.

8. Remove upper protective gloves.

9. Dispose of the top protective gloves in a container for infectious waste-used PPE.

10. Disinfect lower gloves - container with lever control by the elbow min. $30 \mathrm{~s}$.

11. Remove the disposable headgear behind the back.

12. Undress with the help of an assistant-untie the back, undress from back to front, and rolling it up so that the helper does not touch the outside of the coat.

13. Dispose of the disposable jacket in a container for infectious waste-used PPE.

14. Disinfect threaded gloves.

15. Remove safety goggles-put in a container with disinfectant.

16. Disinfect gloves.

17. Leave the infection department.

In total, we created 3 scenarios using VR reality as part of the training process for the use of personal protective equipment in the hospital space. In addition to laboratory tests, we tested these scenarios in practice on the employees of the University Hospital in Pilsen.

\section{Results}

We can divide the results of the research into two groups, the technological and the practical part. Within the technological part, several tests of the created application were carried out from the point of view of its correct functionality. That is, whether the application works correctly, whether its control is in accordance with the requirements, or whether the control using the controller and the like works properly.

\subsection{Tests the Functional Side of the Application}

This type of test was performed by developers and programmers of the XR Institute, which participated in the entire project. During these tests, the following deficiencies were identified:

- As part of a test aimed at the correct use of personal protective equipment, it was not possible to grasp the right glove and place it on the avatar.

- As part of the test to properly remove sharp objects, the syringe remained "hanging" and floating in the air. According to the scenario, it was to be closed in a bio-waste bin.

- $\quad$ After entering the specialized workplace, the user was shown only the inner part of the room (bed, patient, table) but the background of the room was not displayed.

All identified and described shortcomings were eliminated by the development team, and then a control test of the correct functionality of the application was performed. After the given adjustments, it already worked correctly from the content page, which was to be displayed to the user, and of course also from the functional page, no malfunctions or freezing of the application were recorded. 


\subsection{Application Content Page Tests}

Tests of the content of the application, as it is primarily intended for medical staff, were carried out at the University Hospital in Pilsen. The University Hospital in Pilsen is one of the largest and most modern hospital facilities in the Czech Republic. Its size is also indicated by the number of employees, which is shown in Table 2 together with the identification of the number of employees in individual positions [28].

Table 2. Job positions of the Hospital in Pilsen with an expression of the number of employees [28].

\begin{tabular}{cc}
\hline Position Type & Number \\
\hline Number of all hospital employees & 4828 \\
Number of doctors & 989 \\
Number of pharmacists & 31 \\
Number of nurses & 1677 \\
Number of other medical staff & 1272 \\
Number of employees for building management and cleanliness & 469 \\
Number of maintenance workers & 390 \\
\hline
\end{tabular}

As this was a pilot test, we did not involve all employees in it, so as not to take their time; instead, we focused only on nurses. Due to the COVID-19 pandemic, these are being tested relatively intensively, as they have to move between departments, get used to the new environment and new colleagues from other departments, and so on.

We selected a group of 120 nurses for testing, which represents the number of standard wards. The selection was on a voluntary basis, through a notice board and information from superiors. All hospital nurses from any ward were able to participate in the test.

We performed the testing within one day. Testing took place using our application, i.e., VR technology implemented through Oculus Quest 2. At the beginning of the training, the application as well as its controls, environment, and the like were preset. Subsequently, they completed the training through the scenarios presented in the methodology section and, after the training, an online test. Due to the capacity and the limited number of glasses, the test took almost three hours.

The online test focused on the proper handling of bio-waste, the procedure for injuries as well as the use of personal protective equipment, and the total number of questions was 10. We considered the test successful if the score was at least $90 \%$, i.e., if participants had at least 9 correct answers. The results of the tests as well as the comparison between the forms of training are shown in Table 3.

Table 3. Job positions of the Hospital in Pilsen with an expression of the number of employees.

\begin{tabular}{cccc}
\hline & $\begin{array}{c}\text { Number of Nurses } \\
\text { (pcs) }\end{array}$ & Success (pcs) & Success (\%) \\
\hline VR training & 120 & 117 & 97.5 \\
\hline
\end{tabular}

\subsection{Evaluation of Results}

As we can see in Table 3, the training using VR technology had a relatively high success rate. Only three nurses out of a total of 120 failed to obtain at least 9 points in the online test. What is gratifying, however, was that during the retrospective check we found that, of these three nurses, two had 8 points and one had 7 points. Test results are stored within the application, and it is possible to view their values as well as identify incorrect answers. The entire online testing process is based on the Google Forms platform. The fact that most nurses were from the pediatric ward, gynecology and obstetrics ward, or outpatient clinic, i.e., wards in which there is a very low incidence of injuries due to sharp injuries or other types of work accidents, contributes to the significance of the test in real conditions.

As we mentioned, nurses from any department could take part in the pilot test. In fact, they were mainly nurses from outpatient clinics, children's wards, and similar wards, 
which in professional terminology, are understood as "clean wards". They do not require the regular use of a protective coat or other devices, as is the case in the infectious disease ward, so most of the information was new to the trainees.

In addition to the test itself, the participants of the training are regularly checked by the application, and in case of their poorly chosen option, they are assigned so-called "black points", which may ultimately mean an overall impact on the test result. These points are given, for example, for not complying with the time required to disinfect hands when arriving and leaving the infection department. The participant is also notified of this fact by a sound buzzer. If such a scenario is repeated twice in a row, i.e., the participant is notified of the error by a buzzer and does not eliminate it, their test is automatically terminated, evaluated as unsuccessful, and must be attended again.

One of the main benefits of the application is that it can monitor and record the error rate of the participant, which can then define a standard error rate that can be focused on and eliminated. Until now, such a possibility has been unrealistic and has only been investigated in the event of an accident at work or in the event of an error being identified. The second very significant benefit is the use of the application for the newly emerging COVID-19 departments.

\section{Discussion}

Experiential learning has experienced a great deal of interest in recent years, both in the standard form of teaching in schools [29] and in other sectors such as training an employee for a new job. Based on several studies [30,31], we can assume that the human brain better remembers the visual form of training and it has more added value for the human brain than the classical form of writing on a blackboard and talking about first aid administration, for example.

As part of our pilot test, we focused on the hospital environment and the use of personal protective equipment by nurses. We chose this option for several reasons that have already been presented, such as saving on time needed to retrain staff and the fact that not everyone controls the customs and requirements of all departments. In addition, especially in the current COVID-19 situation where there is a large migration of staff, it is an especially suitable option, as it makes it possible to completely eliminate the contact of the training and trained person. When creating the foundations of the training process, we also considered other options besides VR, such as AR. However, based on the primary requirement of the training process, namely OHS, we chose VR because it is a more affordable option than AR. The economic factor was also decisive: in order to create the image, it is necessary to realize that the VR technology we worked with, Oculus Quest 2, can be purchased for approximately EUR 300 in a version with a higher memory capacity. In the case of AR, where Microsoft HoloLens 2 glasses are the standard representative, the purchase price is somewhere around EUR 4000, with procurement being only the initial part. Programming applications for VR is more complicated from the point of view of the developer, the programmer, and it is therefore possible to that higher financial costs are assumed again.

Other reasons for using VR are the possibility to retrain a completely autonomous large number of people at once, centrally managed content, high flexibility depending on the change, the possibility of the sustainability of always updated versions, and content quality and standardization.

As this was a pilot form of the project and our aim is to continue making progress on this project, we asked the test participants to fill out a short questionnaire focused on the suitability and satisfaction with the form of training through the VR. The wording of the questions is given in Table 4 . 
Table 4. Questions and possible answers within the training satisfaction test.

\begin{tabular}{ccc}
\hline & Question & Answer \\
\hline 1. & Gender & Man $/$ Woman \\
2. & How many years have you been working in healthcare? & $0-1 / 1-5 / 5-10 / 10$ and more \\
3. & Have you had experience with VR training before? & Yes/No \\
4. & What do you see as the benefits of VR training? & \\
5. & What do you see as the disadvantages of VR training? & Classic / through the VR \\
6. & What form of training would you present in the future? & \\
\hline
\end{tabular}

In addition to the already-mentioned suitability, we also wanted to know the openness of the older generation towards VR, so instead of the age of the respondents, we wanted to know the length of their internship. In the case of questions 4 and 5, we did not define the possibility of answering, but we left it to the subjective view of the respondent. The results of the questionnaire survey among the test participants are shown in Table 5.

Table 5. Evaluation of the questionnaire survey of VR training respondents.

\begin{tabular}{|c|c|c|c|c|}
\hline \multirow{2}{*}{$\begin{array}{c}\text { Question } \\
\text { Number }\end{array}$} & \multicolumn{4}{|c|}{ Answers } \\
\hline & $\begin{array}{c}\text { Men } \\
19(15.8 \%)\end{array}$ & $\begin{array}{c}\text { Women } \\
111(84.2 \%)\end{array}$ & & \\
\hline 2. & $\begin{array}{c}0-1 \\
11(0.09 \%)\end{array}$ & $\begin{array}{c}1-5 \\
48(0.40 \%)\end{array}$ & $\begin{array}{c}5-10 \\
52(0.43 \%)\end{array}$ & $\begin{array}{c}10 \text { and more } \\
9(0.08 \%)\end{array}$ \\
\hline 3. & $\begin{array}{c}\text { Yes } \\
6(0.05 \%)\end{array}$ & $\begin{array}{c}\text { No } \\
114(0.95 \%)\end{array}$ & & \\
\hline 4. & clarity & speed of seizure & $\begin{array}{l}\text { modern } \\
\text { technologies }\end{array}$ & something new \\
\hline $\begin{array}{l}5 . \\
6 .\end{array}$ & $\begin{array}{l}\text { VR effect } \\
\text { Classic } \\
2(0.01)\end{array}$ & $\begin{array}{c}\text { nothing } \\
\text { Through the VR } \\
118(0.99 \%)\end{array}$ & & \\
\hline
\end{tabular}

As we can see in Table 5, more women than men took part in our test and the most numerous groups in terms of length of practice were between 5 and 10 years. In the case of Questions 4 and 5, where we left the answer form open, we created group names for individual answers within Table 5. For example, if the respondent wrote: "I consider the possibility of seeing the real situation to be positive", we took it as a "clarity" answer in our evaluation.

In the case of the answer to question number 5 on the VR effect, this designation means a group name of possible unpleasant feelings or feelings related to where the user is etc., after using VR technology. This effect occurs especially during the initial uses of the technology.

From our point of view, it is gratifying that all but two of the test participants would welcome a form of training through VR technology in the future. Of these two people, one has a range of $0-1$ years and the other 1-5 years, which means that people with a longer length of experience are in favor of using VR technology for training.

As we mentioned in the "results" section, the participants in the pilot test were tested in the form of an online test but also based on mistakes made during the training. We decided to choose the online test as it is still used today and implemented during each and every repeated health and safety training. There are suspicions that it could be a formal matter, or even the group work of the trainees in completing it, thus losing its effect and meaning. In the future, it would be possible to use the educational system we created, thus preventing such suspicion. The results would be fully electronic, and superiors would have access to them and would be informed about the real abilities of their employees. 


\section{Conclusions}

The aim of the research was to combine the benefits of the ever-evolving VR technology and education in the proper use of personal protective equipment in the healthcare sector. For this purpose, an expert consortium was formed consisting of representatives of companies such as the Ministry of Labour and Social Affairs of the Czech Republic, University Hospital in Pilsen, XR Institute, and Guard7. Based on the knowledge and requirements of both hospital staff and Guard7 employees, we created three basic scenarios focused on handling of sharps, sharps injuries, and entering a specialized workplace, focusing on the possibilities of prevention against COVID-19 among staff in these scenarios. The use of protective equipment, such as the correct procedure for donning gloves, gowns, or protective shields, was also an integral part of these scenarios. From several points of view, especially financial, we decided to create an application for VR and not for other types of reality.

The scenarios thus created were then subjected to laboratory tests in which we focused on correct functionality and evaluation of the executed instructions. Subsequently, we also familiarized the system to the staff of the University Hospital in Pilsen, who took part in a pilot test on a voluntary basis with 120 nurses from various departments of the hospital. A feedback questionnaire also contributed as part of the feedback verification of the suitability of the use of VR technology for training. From the questionnaire, we noted that up to $99 \%$ of test participants, i.e., 118, would repeat the training through VR. The fact that the success rate was $97.5 \%$ for the overall test after completing the training, i.e., 117 participants were successful, also speaks of the advantage or the right choice of the training form. Everyone who scored at least 9 out of 10 points in the test was considered successful.

Following the achieved results, we decided to create further scenarios applicable in the healthcare segment in order to expand our system to all hospitals in the Czech Republic. Currently, the consortium has been expanded to include the Faculty of Security Engineering of UNIZA, and, in addition to the medical segment, we are focusing on the general use of personal protective equipment in all professions.

Author Contributions: Conceptualization, M.B. (Martin Boros), E.S., A.C., M.B. (Marek Bardy) and K.B.; methodology, A.C., M.B. (Marek Bardy) and M.B. (Martin Boros); software, M.B. (Martin Boros) and M.B. (Marek Bardy); validation, E.S., A.C. and K.B.; formal analysis, A.C. and K.B.; investigation, E.S.; resources, M.B. (Martin Boros) and M.B. (Marek Bardy); data curation, M.B. (Martin Boros); writing—original draft preparation, M.B. (Martin Boros); writing—review and editing, E.S., A.C. and K.B.; visualization, A.C.; supervision, M.B. (Martin Boros); project administration, A.C.; funding acquisition, A.C. and M.B. (Marek Bardy). All authors have read and agreed to the published version of the manuscript.

Funding: This research was funded by Institutional support for the long-term conceptual development of the research organization for the years 2018-2022 and is part of the project Health and Safety in Virtual Reality No. 11-S4-2021-VUBP, and by Slovak research and development agency grant number APVV-20-0603 Development of Risk Assessment Tools for Selected Businesses and Professions in the Slovak Republic in accordance with the EU Requirements.

Data Availability Statement: Data are contained within the article.

Conflicts of Interest: The authors declare no conflict of interest.

\section{References}

1. Dzaranova, E.; Kasapakis, V.; Gavalas, D.; Sylaiou, S. Virtual reality as a communication medium: A comparative study of forced compliance in virtual reality versus physical world. Virtual Real. 2021. [CrossRef]

2. Margetis, G.; Apostolakis, K.C.; Ntoa, S.; Papagiannakis, G.; Stephanidis, C. X-Reality Museums: Unifying the Virtual and Real World Towards Realistic Virtual Museums. Appl. Sci. 2021, 11, 338. [CrossRef]

3. Bec, A.; Moyle, B.; Schaffer, V.; Timms, K. Virtual reality and mixed reality for second chance tourism. Tour. Manag. 2021, 83, 104256. [CrossRef]

4. Xing, Y.K.; Liang, Z.T.; Fahy, C.; Shell, J.; Guan, K.; Liu, Y.; Zhang, Q. Virtual Reality Research: Design Virtual Education System for Epidemic (COVID-19) Knowledge to Public. Appl. Sci. 2021, 11, 10586. [CrossRef] 
5. Newzoo: Globální trh s Hrami Letos Vygeneruje Přes 150 Miliard USD. Available online: https://www.rmol.cz/novinky/ newzoo-globalni-trh-s-hrami-letos-vygeneruje-pres-150-miliard-usd (accessed on 12 September 2021).

6. Asian Games 2022: Esports to Make Debut; FIFA, PUBG, Dota 2 among Eight Medal Events. Available online: https://olympics. $\mathrm{com} / \mathrm{en} /$ news/ fifa-pubg-dota-2-esports-medal-events-asian-games-2022 (accessed on 20 September 2021).

7. Velas, A.; Holla, K.; Boros, M.; Pluktiate, J. Utilising the virtual and augmented reality in the educational process in the safety area. In Proceedings of the International Conference on Education and New Learning Technologies, Palma, Spain, 7 July 2021; ISBN 978-84-09-31267-2.

8. Li, G.; Rempel, D.; Liu, Y.; Song, W.; Adamson, C.H. Design of 3D Microgestures for Commands in Virtual Reality or Augmented Reality. Appl. Sci. 2021, 11, 6375. [CrossRef]

9. Longo, U.G.; De Salvatore, S.; Candela, V.; Zollo, G.; Calabrese, G.; Fioravanti, S.; Giannone, L.; Marchetti, A.; De Marinis, M.G.; Denaro, V. Augmented Reality, Virtual Reality and Artificial Intelligence in Orthopedic Surgery: A Systematic Review. Appl. Sci. 2021, 11, 3253. [CrossRef]

10. Qin, Z.B.; Tai, Y.H.; Xia, C.Q.; Peng, J.; Huang, X.; Chen, Z.; Li, Q.; Shi, J. Towards Virtual VATS, Face, and Construct Evaluation for Peg Transfer Training of Box, VR, AR, and MR Trainer. J. Healthc. Eng. 2019, 2019, 6813719. [CrossRef] [PubMed]

11. Carrasco, M.D.O.; Chen, P.H. Application of mixed reality for improving architectural design comprehension effectiveness. Autom. Constr. 2021, 126, 103677. [CrossRef]

12. Li, J.H.; Zhang, H.X.; Li, Q.; Yu, S.Q. Treating Lumbar Fracture Using the Mixed Reality Technique. Biomed Res. Int. 2021, 2021, 6620746. [CrossRef]

13. Vidal, R. Design and Implementation of High Reliability Organizing Based Performance Metrics in the Context of the EU H2020 Research Project TARGET, Aiming at Developing VR/AR Training Environment for Security Critical Agents. Congr. Int.-Ergon.-Assoc. 2019, 824, 1850-1859.

14. Fanfarova, A.; Maris, L. Virtual and augmented reality in education and training of firefighters. In Proceedings of the International Conference on Education and New Learning Technologies, Palma, Spain, 2-4 July 2018; ISBN 978-84-09-02709-5.

15. Virtual Reality Market Size, Share \& Trends Analysis Report By Technology (Semi \& Fully Immersive, Non-immersive), By Device (HMD, GTD), By Component (Hardware, Software), By Application, And Segment Forecasts, 2021-2028. Available online: https:/ / www.grandviewresearch.com/industry-analysis/virtual-reality-vr-market (accessed on 18 September 2021).

16. Augmented and Virtual Reality Market by Organization Size, (Large Enterprises and Small \& Medium Sized Enterprises), Application, (Consumer and Enterprise), and Industry Vertical (Gaming, Entertainment \& Media, Aerospace \& Defense, Healthcare, Education, Manufacturing, Retail, and Others): Global Opportunity Analysis and Industry Forecast, 2021-2030. Available online: https:/ / www.alliedmarketresearch.com/augmented-and-virtual-reality-market (accessed on 18 September 2021).

17. Google Maps AR: Navigácia s Rozšírenou Realitou. Available online: https:/ / fony.dnes24.sk/clanky/15053-google-maps-arnavigacia-s-rozsirenou-realitou (accessed on 28 September 2021).

18. Kelly, S.; Duffy, M.B.; Ruiz, P. Experiential Learning for Undergraduate Nursing Students: Engagement With a University Health Center. J. Nurs. Educ. 2021, 60, 289-292. [CrossRef] [PubMed]

19. Kober, S.E.; Settgast, V.; Brunnhofer, M.; Augsdorfer, U.; Wood, G. Move your virtual body: Differences and similarities in brain activation patterns during hand movements in real world and virtual reality. Virtual Real. 2021. [CrossRef]

20. Korucu-Kis, S. Preparing student teachers for real classrooms through virtual vicarious experiences of critical incidents during remote practicum: A meaningful-experiential learning perspective. Educ. Inf. Technol. 2021, 26, 6949-6971. [CrossRef] [PubMed]

21. Zero Hour: America's Medic. Available online: https:/ /www.ara.com/zero-hour-americas-medic/ (accessed on 28 September 2021).

22. Arlati, S.; Keijsers, N.; Paolini, G.; Ferrigno, G.; Sacco, M. Kinematics of aimed movements in ecological immersive virtual reality: A comparative study with real world. Virtual Real. 2021. [CrossRef]

23. Ministry of Health of the Czech Republic. Personal Consultation; Ministry of Health of the Czech Republic: Nové Město, Czechia, 2021.

24. Costa, C.R.B.; Melo, E.S.; Reis, R.K. Simulation of Emergency Training for Nursing Students. Rev. Cuid. 2020, 11, e853. [CrossRef]

25. Ismailoglu, E.G.; Ozdemir, H. Factors Affecting Sleep Hygiene Training of Nursing Students. J. Turk. Sleep Med.-Turk Uyku Tibbi Derg. 2020, 7, 195-200. [CrossRef]

26. Ong, M.W.; Hwang, J.; Lim, S.M.; Sng, J. Knowledge, attitudes and behaviour towards needlestick injuries among junior doctors. Occup. Med.-Oxf. 2019, 69, 436-440. [CrossRef]

27. Torjesen, I. COVID-19: Doctors should be alert for signs of myocardial injury, says NICE. BMJ-Br. Med. J. 2020, 369 , m1639. [CrossRef]

28. Annual Management Report, University Hospital in Pilsen. Available online: https://www.fnplzen.cz/sites/default/files/ dokumenty / rocni_zpravy /2019.pdf (accessed on 28 September 2021).

29. Bouilheres, F.; Le, L.T.V.H.; McDonald, S.; Nkhoma, C.; Jandug-Montera, L. Defining student learning experience through blended learning. Educ. Inf. Technol. 2020, 25, 3049-3069. [CrossRef]

30. Love, J.N.; Messman, A.M.; Merritt, C. Improving the Learning Experience through Evidence-based Education. West. J. Emerg. Med. 2019, 20, 1-5. [CrossRef]

31. Tran, T.P.; Meacheam, D. Enhancing Learners' Experience Through Extending Learning Systems. IEEE Trans. Learn. Technol. 2020, 13, 540-551. [CrossRef] 